\title{
SLIDING WEAR RESISTANCE OF SINTERED SiC-FIBRE BONDED CERAMICS
}

M. C. Vera ${ }^{1}$, J. Ramirez-Rico ${ }^{1 *}$, J. Martinez-Fernandez ${ }^{1}$, M. Singh ${ }^{2}$

${ }^{1}$ Dpto. Física de la Materia Condensada-ICMS

Universidad de Sevilla-CSIC, Sevilla, Spain

${ }^{2}$ Ohio Aerospace Institute, Cleveland, $\mathrm{OH}$

\begin{abstract}
.
Advanced SiC-based ceramics and fibre reinforced composites are interesting materials for a wide variety of applications involving sliding wear conditions because of their excellent thermomechanical properties. The microstructure and wear resistance of sintered SiC fibre bonded ceramics (SA Tyrannohex) was studied. The material is composed by SiC-fibres in two orientations, with polygonal cross sections and cores having higher carbon content than their surroundings, as observed with SEM. A thin layer of $\mathrm{C}$ exists between the fibres. This layer has been found to be a turbostraticlayered structure oriented parallel to the fibre surface. XRD shows that the material is highly crystalline and composed mostly of $\beta$-SiC. Unlubricated wear behaviour of the SA-Tyrannohex material when sliding against a $\mathrm{Si}_{3} \mathrm{~N}_{4}$ ball in air at room temperature was evaluated. Experiments were performed using a pin on disk apparatus, under different normal loads, 2, 5 and $10 \mathrm{~N}$ at sliding speeds of 25, 50, $100 \mathrm{~mm} / \mathrm{s}$. A decrease of the friction coefficient with load was found due to the presence of the turbostratic carbon layer between the fibres. Wear rates of the order of $100 \mathrm{~mm}^{3} / \mathrm{MJ}$ were obtained, independently of sliding speed. Microfracture of the fibres is the main wear mechanism.
\end{abstract}

Keywords: Silicon carbide; wear; composites; fibres

\section{Introduction}

Ceramics are finding increasing utility in tribological applications like gas turbine components [1], cutting tools [2, 3], or braking systems, especially those to be used at high temperatures and in aggressive environments due to its chemical stability

\footnotetext{
* Corresponding author, email: jrr@us.es, Tel. +34 954 550963, Avda. Reina Mercedes S/N 41012 Sevilla, Spain.
} 
and good abrasive resistance at elevated temperatures. However, low toughness is the cause of their limited reliability.

Ceramic Matrix Composites (CMCs), apart from the good properties of monolithic ceramics like low density, high melt point and high temperature stability, exhibit high tenacity due to their microstructural design. These properties make CMCs leading candidates for numerous applications as structural elements in high-temperature environments. The interest in CMCs is especially relevant in the aerospace industry due to their high fracture toughness and good specific mechanical strength and creep resistance, allowing higher thrust-to-density ratios than metal-based systems [4]. For these reasons, CMCs are currently used in strategic applications such as structural elements in gas turbines [5] and aerojets [6], thermal protection in re-entry vehicles [7] or advanced friction systems [8].

An increasing number of the aforementioned applications involve sliding wear conditions [9], where both matrix and fibres properties must be taken into account to prevent severe wear. Krenkel et al. found that carbon fibres lead to an improved damage tolerance in comparison to monolithic SiC, whereas a silicon carbide matrix improves wear resistance compared to carbon/carbon composites [8].Particularly, CMCs with SiC fibres in a $\mathrm{SiC}$ matrix ( $\mathrm{SiC} / \mathrm{SiC}$ ) present a very high maximum operating temperature in oxidizing environments due to the initial formation of a $\mathrm{SiO}_{2}$ layer that acts as a diffusional barrier for $\mathrm{O}_{2}$. The $\mathrm{SA}$-Tyranno $\mathrm{SiC}$ fibres, developed by Ube Industries Ltd., are good for a variety of applications due to their high crystallinity and low oxygen content, which imparts them with enhanced creep resistance, and the incorporation of $\mathrm{Al}$ ions that enhance their resistance to oxidation and chemical attack by glassy and alkaline deposits [10-13]. In addition, their dense sintered structure composed of nearly stoichiometric SiC crystals [10,14] gives these fibres high thermal stability.

Although CMCs can result in a composite with the potential of enhancing tribological performance, their usage is often limited due to their high manufacturing costs. Fibrous ceramic SiC monoliths obtained from hot-press sintering of fibres are a cost effective alternative to $\mathrm{SiC} / \mathrm{SiC}$ ceramic matrix composites. In this work we study the SA-Tyrannohex material which is obtained through hot pressing of stacked, woven SA-Tyranno fibres mats [10-13] and has several advantages over conventional CMCs. For instance, SA-Tyrannohex is significantly cheaper to manufacture than CMCs since 
their fabrication involves fewer processing steps, and can be made into complex shapes by laying up the fibre mats into shapers, molds or preforms. Sintering additives such as $\mathrm{Al}$ are already present and uniformly distributed in the fibre precursors, while the carbon interfacial layer required for enhanced toughness in CMCs appears in-situ during processing. Full densities are nearly achieved and the absence of pores and defects results in good mechanical properties, excellent thermomechanical performance [15] and great oxidation resistance at temperatures up to $1600^{\circ} \mathrm{C}$ [16].The presence of a very high interface density imparts high fracture toughness. In sliding contact, the dominant wear mechanism of ceramics in dry atmospheres is microfracture $[17,18]$. Penetration of a harder solid into the surface of the ceramic does not occur and toughness is the main determinant of wear resistance. Khedkar et al. showed that composites with higher heat absorption capacity exhibited improved wear resistance [19]. SA-Tyrannohex has relatively high thermal conductivity at temperatures above $1000^{\circ} \mathrm{C}$, in the fibre direction and in the orthogonal direction, compared with other materials including some $\mathrm{SiC} / \mathrm{SiC}$ composites (CVI) and $\mathrm{Al}_{2} \mathrm{O}_{3}$ and metals [10].

There is very limited previous work on the wear resistance of SiC/SiC ceramic composites, and thus the purpose of the present investigation was to study the tribological behaviour of the SA-Tyrannohex material when sliding against $\mathrm{Si}_{3} \mathrm{~N}_{4}$ in air at room temperature.

\section{Materials and Methods.}

Commercial SA-Tyrannohex billets measuring $(1 \times 2.5 \times 2.5) \mathrm{cm}^{3}$ were obtained from Ube Industries (Yamaguchi, Japan). Table 1 includes a summary of mechanical and thermal properties of this material as provided by the supplier. Samples for wear tests were cut into slices with a thickness of $1.5 \mathrm{~mm}$ using a low speed diamond saw. Specimen for SEM and XRD observation were prepared by conventional metallographic techniques.

Friction experiments were performed on a pin-on-disk tribometer (Microtest MT3, Madrid, Spain) consisting of stationary pin sliding on rotating disk in accordance with ASTM G99. A ball on disk geometry was chosen to avoid misalignment problems. Slices of the SA-Tyrannohex material were polished to a $R_{a}$ value of $0.7 \mu \mathrm{m}$ and used as disks. Commercially available $6 \mathrm{~mm}$ diameter $\mathrm{Si}_{3} \mathrm{~N}_{4}$ balls were used as counter surface. Both disks and balls were cleaned in acetone in an ultrasonic bath for 10 minutes and 
dried in air prior to use. Tests were carried out at a constant sliding speed of $100 \mathrm{~mm} / \mathrm{s}$ under three different normal loads 10,5 and $2 \mathrm{~N}$ to evaluate the influence of the applied load on the friction coefficient. To study the dependence with the sliding speed, experiments were carried out under a load of $5 \mathrm{~N}$ at three different sliding speeds, 100, 50 and $25 \mathrm{~mm} / \mathrm{s}$. The normal loads were applied parallel to the pressing direction of the SA-Tyrannohex. The friction coefficient is the ratio $\mathrm{F} / \mathrm{L}$, were $\mathrm{F}$ is the friction force measured with a precision of $0.010 \mathrm{~N}$ and $\mathrm{L}$ the normal load. The tests were performed at ambient conditions (51-53\% RH, $27^{\circ} \mathrm{C} \mathrm{RT}$ ) in air without lubrication. Wear tests were run for $800 \mathrm{~m}$ in most cases with the exception of the tests where excessive wear was experienced by the ball, which were terminated prematurely. Total displacement of the $\mathrm{Si}_{3} \mathrm{~N}_{4}$ ball relative to SA-Tyrannohex disk was measured during the tests by a capacitive displacement sensor attached at the tribometer arm carrier with a precision of $0.02 \mathrm{~mm}$. This value represents the worn track depth of the material plus wear depth of the ball (see Figure 1).

Surface topography of the SA-Tyrannohex specimen after tribological tests was measured with a stylus-type profilometer. As the cross section profile of a wear track cannot be assumed to be uniform, profilometer traces across each wear scar at eight representative positions were obtained and averaged together. The volume of the worn out material was calculated by multiplying the averaged cross section area of the wear track times the length of the wear track. The specific wear rate is calculated as $\mathrm{k}=\mathrm{V} /(\mathrm{Ld})$, were $\mathrm{V}$ is the volume of material worn, $\mathrm{L}$ the normal load and $\mathrm{d}$ the sliding distance. Wear rate of the $\mathrm{Si}_{3} \mathrm{~N}_{4}$ balls was calculated in the same way. The volume loss in this case was calculated by means of geometrical arguments after measuring the radius of the near-circular scars on the balls with an optical microscope. Worn surfaces of the SA-Tyrannohex material were observed by SEM after cleaning them with compressed air.

\section{Results and Discussion.}

\subsection{Microstructure.}

Figure 2 shows a representative cross-section of the as-fabricated material in backscattered electrons contrast, in a plane containing the fibre mat stacking direction (a) and in a plane perpendicular to this pressing direction (b). Fibres of $\sim 8-10 \mu \mathrm{m}$ in diameter in both orientations are clearly visible with a very thin interfacial carbon layer 
between them. This layer has been found to be a turbostratic-layered structure oriented parallel to the fibre surface [11]. Turbostratic carbon consists of disordered graphite, lacking the order of stacked graphene [20], and this layer will be shown to be essential for the wear resistance of the material. Fibres show polygonal cross sections characteristic of the sintering process, and some pores and voids are observed at triple points. The material density was measured using a He pycnometer and a value of $3.0687 \pm 0.0009 \mathrm{~g} \mathrm{~cm}^{-3}$ was obtained. Darker contrast in the core of the fibres is indicative of a concentration gradient, and the cores were determined by EDS to have higher carbon content than their surroundings. The observed concentration gradient probably occurs during the fibre sintering step and could be due to differences in diffusivity between the species involved. The microstructure of the Tyranno-SA fibres consists of SiC grains of $\sim 200 \mathrm{~nm}$ in diameter, with a considerable amount of free pyrolytic carbon at triple points which is homogeneously distributed in the fibre [14].

Figure 3 shows X-Ray diffraction patterns of the as fabricated SA-Tyrannohex in and out of the fibre plane. XRD shows that the material is highly crystalline and composed mostly of $\beta$-SiC with small amounts of h-graphite. This broad graphite peak is due to the presence of the carbon interfacial layer between the fibres. Differences in the relative intensity of the peaks for both orientations are indicative of a possible crystallographic texture.

\subsection{Tribological behaviour.}

\subsubsection{Influence of normal load.}

To study the effect of the applied load on friction coefficient and wear resistance, the results of tests carried out under normal loads of 10,5 and $2 \mathrm{~N}$ at a constant sliding speed of $100 \mathrm{~mm} / \mathrm{s}$ are analysed here.

Figure 4 shows the variation in the friction coefficient of the SA-Tyrannohex material versus sliding distance for the three loads studied where it can be observed that the friction coefficient does not reach a steady value during the tests. This could be attributed to changes in contact geometry during the tests when fibres are fractured, as will be discussed below.. Mean value of the last 20 measurements of the friction coefficient was calculated as $0.618 \pm 0.009,0.570 \pm 0.005$ and $0.541 \pm 0.007$ for a normal load of 2, 5 and $10 \mathrm{~N}$ respectively. The response of materials to this kind of experiments 
depends not only on the precise nature of the materials in relative movement, but also on the detailed conditions of the contact between them and of the motion. That makes it difficult to compare laboratory results from different studies. Similar dry sliding pin on disk tests compiled by Munro [21] when the load is $\leq 10 \mathrm{~N}$ and the sliding speed is $\leq 250$ $\mathrm{mm} / \mathrm{s}$ under different test configurations shows that the friction coefficient of sintered $\alpha$ $\mathrm{SiC}$ ranges from 0.5 to 0.8 at $\mathrm{RT}$, values which are slightly higher than those of the SATyrannohex. The friction coefficient appears to be weakly dependent on the applied load, and decreases with increasing load. This decrease could be due to the presence of the interfacial carbon layer between the Tyranno-SA fibres, as more carbon debris is produced during friction with higher loads. Graphite is a well-known solid lubricant in air because weak bonding (Van der Waals forces) between the planes provides low shear strength in the direction of the sliding movement [22]. Friction forces cause the graphite particles to orient in the direction in which the graphite planes are parallel to the sliding movement. Furthermore, tests were done in a moist atmosphere $(\mathrm{RH}=51$ $53 \%)$, probably causing water molecules to adsorb on the carbon surface resulting in further reduction of the bonding between the graphene planes. In addition, when temperature rises at the mating surface, the high thermal conductivity of SATyrannohex might help retain moisture for graphite to act as a lubricant.

Figure 5 shows a plot of total displacement of the $\mathrm{Si}_{3} \mathrm{~N}_{4}$ ball relative to the SATyrannohex disk versus sliding distance under the different applied loads. The change in the distance between the two triboelements is the sum of the linear wear contributions from both of them (see Figure 1), and increases with increasing load. In an attempt to separate the contribution of each triboelement, balls were observed in an optical microscope. Subtraction of linear wear of the ball to the measurements of the total displacement leads to values of $\sim 10 \mu \mathrm{m}$, which is less than the precision of the displacement sensor $( \pm 20 \mu \mathrm{m})$. Then, magnitude of wear scar depth of SA-Tyrannohex material is of the order of tens of microns but this technique is not appropriate to quantify it. Apart from this, these measurements does not take into account the fact that the material being removed from a triboelement might also partially be depositing within wear tracks or might be sticking to the counterface. Thus one would actually be measuring only an apparent total displacement between the two triboelements. Finally, that is not a good way to quantify wear. In order to quantify wear rate, surface topography of the disks after the tribological tests was measured with a stylus type 
profilometer. Profiles of worn surface of the SA-Tyrannohex material after the tests are shown in Figure 6.a). The worn track depth increases with the increase in the applied load. Ordinarily, a high load implies a high shear stress on the sliding surface which should produce more fracture. This explains the increase in wear with the increase in load if the dominant wear mechanism is microfracture.

Wear rate of the two triboelements versus normal load is presented in Figure 6.b). Inhomogeneity of the microstructure of the SA Tyrannohex material makes the cross section profile of each wear track was highly variable and position dependent. Variation in the profilometer measurements of the worn track depth was $\pm 10 \mu \mathrm{m}$, due to one more fibre is fractured or not, depending on the position. Worn track depth is the same order of magnitude of the fibres' diameter. This is the origin of the large uncertainty of these measurements. Wear rate of the SA-Tyrannohex material can be considered independent of the applied load when taking this uncertainty into account. No dependence with load is indicative of elastic instead of plastic deformation taking place. Krenkel et al., simulating real conditions of braking systems for C/C-SiC composites [8], found wear rates the same order of magnitude than that of the SATyrannohex, $100 \mathrm{~mm}^{3} / \mathrm{MJ}$. These values of wear rate are closely related to microstructure of the material. The high fibre volume fraction and the existence of a strictly controlled interphase provides the material with a much higher fracture energy than monolithic ceramics [10]. This structure is effective in preventing the large-scale fragmentation of the material, resulting in formation of small discontinuous fragments and thereby reducing the overall wear rate. Wear rate of the $\mathrm{Si}_{3} \mathrm{~N}_{4}$ ball is an order of magnitude smaller than that of the SA-Tyrannohex material but considerable wear occurs due to the fractured SA fibres causing abrasion to the contact surface of the ball.

Figure 7 shows SEM micrographs of worn surfaces of the SA-Tyrannohex material after tests carried out under normal loads of 2 (a), 5 (b) and 10N (c) respectively. Notice that fibres in two perpendicular directions exist in all the surface of the material (see Figure 2.b) therefore, along the scar the sliding direction forms different angles with these fibres. Wear evidences no dependence with respect to fibre orientation. As shown in the micrographs, there is no presence of particles attached to the surface and fracture of fibres occurs, indicating that loss of material is caused by fibre pull out and fibre fragmentation. In Figure 7.b), where a region inside a wear track is shown, is clearly visible that two layers of fibres have fractured, which is in 
agreement with the scar depth measured by the profilometer (Figure 6. b)), as fibres are $\sim 10 \mu \mathrm{m}$ in diameter. In figure 7. f) a fractured fibre is observed. That confirms the dominant wear mechanism of the material is microfracture. In this material, the turbostratic carbon layer between the fibres is easily removed by the friction force and that makes fibres without an interfacial layer to deflect cracks support the high contact stresses until failure. Fischer et al. [18] proposed for $\mathrm{Si}_{3} \mathrm{~N}_{4}$ in sliding contact in intermediate humidity air ( 40\%) wear occurs by a combination of fracture and chemical reactions. In this study, we have used energy dispersive spectroscopy in the SEM to test for the presence of oxidation but we have not observed any tribochemical film on the worn surfaces. If temperatures in the contact area were high enough oxidation of the fibres' surface and/or the free C could occur. In any case, these oxidized fibres will be eventually fractured according to SEM observations, so microfracture and not oxidation will be the main mechanism producing wear. Absence of C between fibres due to oxidation of this interlayer would make fibres' fracture more favourable as explained previously3.2.2. Influence of sliding speed.

Results of tests carried out under a normal load of $5 \mathrm{~N}$ at a constant sliding speed of 25, 50 and $100 \mathrm{~mm} / \mathrm{s}$ respectively are analysed here to study the effect of the sliding speed on friction coefficient and wear rate.

Figure 8 shows the friction coefficient of the SA-Tyrannohex material versus sliding distance for the three sliding speeds tested. Dependence of friction coefficient with sliding distance shows that the lower the sliding speed, the shorter the sliding distance is from beginning to stabilization. The magnitude of the friction coefficient for the speeds of 25 and $50 \mathrm{~mm} / \mathrm{s}$ are very close and higher than that for the speed of 100 $\mathrm{mm} / \mathrm{s}$. Mean value of the last 20 measurements of friction coefficient is $0.610 \pm 0.009$, $0.614 \pm 0.007$ and $0.570 \pm 0.005$ for a sliding speed of 25,50 and $100 \mathrm{~mm} / \mathrm{s}$ respectively. There are no results in literature for friction coefficient of $\mathrm{SiC}$ against $\mathrm{Si}_{3} \mathrm{~N}_{4}$ measured in identical conditions as those studied here. For similar tests, results are analogous. A coefficient of friction of 0.6 is obtained by Ajayi et al. [23] for a hot-pressed $\mathrm{SiC}$ with a diamond ball as a counter surface, loads between 1 and $30 \mathrm{~N}$ and low sliding speeds ( $<0.1 \mathrm{~mm} / \mathrm{s}$ ). When a sliding contact passes a spot on a surface, the temperature on the surface rises due to frictional heating and a rapid cooling down follows due to heat dissipation. The temperature rise will induce thermal strain and therefore compressive stress at the surface. As the sliding speed increases, local temperature elevations at the 
wear interface are bigger [24] so fracture induced by thermal shock is more likely. For this reason the friction coefficient might decrease with increasing speed due to material exhibiting less resistance to the sliding ball. In the range of velocities analysed here, the friction coefficient of the SA-Tyrannohex material shows no dependence with sliding speed except a slight decrease with the highest speed, consistent with the data for sintered SiC compiled by Munro [21]. Although high thermal conductivity of the material (77.7-36.4 W/mK in plane and 44.8-23.6 W/mK out plane over RT-1400 ${ }^{\circ} \mathrm{C}$ ) and relative low thermal expansion coefficient in plane (3.20-4.66 $10^{-6} \mathrm{~K}^{-1}$ over 20$1600^{\circ} \mathrm{C}$ ) might result in high thermal shock resistance and explain no dependence of friction coefficient with sliding speed, fracture induced by thermal shock is a possible wear mechanism due to other factors like high elastic modulus (310-200 GPa over 20$1600^{\circ} \mathrm{C}$ ). It would be necessary to make temperature measurements at the counter surface and further testing at sliding speeds above $100 \mathrm{~mm} / \mathrm{s}$ in order to find out if there is a critical value of the sliding speed at which thermal shock is an important agent producing wear and causing significant variations in friction coefficient values.

Figure 9 shows total displacement of the $\mathrm{Si}_{3} \mathrm{~N}_{4}$ ball relative to the SATyrannohex disk versus sliding distance at the different sliding speeds. This distance decreases slightly when the sliding speed increases but the magnitude of this decrease is smaller than the resolution of the displacement sensor. We can then conclude that the sum of the linear wear contributions from both elements shows no dependence with speed. For the same reasons exposed previously, it is not possible to separate contribution of wear of each triboelement to the change in this distance and it is not a good way to quantify wear. It is necessary to look at the profile meter's measurements to study the effect of sliding speed on wear of the SA-Tyrannohex material. Surface profiles of worn surfaces of the SA-Tyrannohex material after the tests performed under a normal load of $5 \mathrm{~N}$ show that worn track depths and widths are similar for the sliding speeds of 25 and 50 mm/s and larger for the highest velocity studied(see Figure 10.a)).

Wear rate of the two triboelements versus sliding speed for the experiments carried out under a normal load of $5 \mathrm{~N}$ is presented in Figure 10.b). Uncertainty is due to reasons previously explained. Wear rate of the SA-Tyrannohex slightly decreases when duplicating speed and then increases when increasing speed again, but it can be considered constant with the speed taking the uncertainty in these measurements into account. Slight dependence of wear rate with sliding speed could be due to the hardness 
of the SA-Tyrannohex material might be little sensitive to temperature changes. Data on hardness of the material versus temperature are not available yet but $\mathrm{H}$. L. Wang et al. [25] found that degradation in hardness of ceramics with increasing temperature correlates well with thermal expansion behaviour, so material with larger thermal expansion coefficient will soften more rapidly than those with lower CTE values. Our $\mathrm{SiC}$ material has a thermal expansion coefficient (in plane) of $3.20-4.66 \cdot 10^{-6} \mathrm{~K}^{-1}$ over $20-1600^{\circ} \mathrm{C}$, that is low in comparison with ceramics included in the aforementioned study. Measured wear rates were as low as $\sim 100 \mathrm{~mm}^{3} / \mathrm{MJ}$, even for the highest studied sliding speed, which could be due to the expected high thermal shock resistance of the material. Esposito et al. [26] showed that zirconia based ceramics suffer severe wear at high sliding speeds above $200 \mathrm{~mm} / \mathrm{s}$, due to low thermal shock resistance of zirconia. Wear rate magnitude of the $\mathrm{Si}_{3} \mathrm{~N}_{4}$ ball is constant for all the sliding speeds and it is an order of magnitude smaller than that of the SA-Tyrannohex material.

\section{Conclusions.}

Microstructure and wear resistance of sintered SiC fibre-bonded ceramics fabricated by Ube Industries was studied. The SA-Tyrannohex material is composed by SiC-fibres in two perpendicular orientations, with polygonal cross sections and cores having higher carbon content than their surroundings, as observed in the SEM. A thin layer composed of $\mathrm{C}$ exists between the fibres. This layer has been found to be a turbostratic-layered structure oriented parallel to the fibre surface. XRD shows that the material is highly crystalline and composed mostly of $\beta$-SiC.

Unlubricated wear behaviour of the SA-Tyrannohex material when sliding against a $\mathrm{Si}_{3} \mathrm{~N}_{4}$ ball in air at room temperature was evaluated. Experiments were performed using a pin on disk apparatus, under different normal loads, 2, 5 and $10 \mathrm{~N}$ at sliding speeds of 25, 50 and $100 \mathrm{~mm} / \mathrm{s}$. The main findings could be summarized as follows:

- A decrease of the friction coefficient of the material with load was found due to the presence of the turbostratic carbon layer between the fibres. C debris, larger with higher load, act as a solid lubricant reducing friction.

- Friction coefficient shows no significant dependence with sliding speed in the range of 25-100 mm/s possibly due to the expected high thermal shock resistance of the material. 
Higher speeds must be studied to determine the existence of a critical value of velocity above which some dependence is observed.

- Wear rates of the order of $100 \mathrm{~mm}^{3} / \mathrm{MJ}$ were obtained. Microfracture of the fibres is the main wear mechanism in all cases. No dependence with fibres orientation was found. The high fracture energy, high thermal conductivity and low thermal expansion of the SA-Tyrannohex material helps to avoid severe wear.

The data reported here is the first for SiC-fibre bonded ceramic materials to the best of our knowledge and will serve to evaluate friction related applications for this new family of ceramic materials. Although the friction coefficient is lower than for sintered $\mathrm{SiC}$ thanks to the presence of free carbon in the microstructure, the trade-off is a larger wear rate due to microfracture and debonding of the fibres.

\section{Acknowledgements.}

The authors thank Dr. T. Ishikawa and T. Matsunaga for providing materials for testing, and Prof. R. Asthana for fruitful discussions. SEM, XRD observation and tribological tests were performed at CITIUS (Universidad de Sevilla). Profile meter measurements were carried out at ICMS (CSIC) with the help and advice of Dr. J. C. Sánchez-López. M C. Vera gratefully acknowledges funding from the Spanish Ministerio de Educación, Cultura y Deporte under a FPU grant.

\section{Tables}

Table 1. Summary of the mechanical properties of SA-Tyrannohex fibre-bonded SiC ceramic, as provided by the manufacturer. 


\begin{tabular}{|c|c|c|c|c|c|c|}
\hline Properties & Unit & RT & $1400^{\circ} \mathrm{C}$ & $1500^{\circ} \mathrm{C}$ & $1600^{\circ} \mathrm{C}$ & $1700^{\circ} \mathrm{C}$ \\
\hline Fibre Volume fraction & Vol \% & $98 \sim$ & & & & \\
\hline Porosity & Vol \% & $<1$ & & & & \\
\hline Density & $\mathrm{g} \cdot \mathrm{cm}^{-3}$ & 3.1 & & & & \\
\hline Tensile Strength (in air) & MPa & 180 & & 180 & 160 & \\
\hline Young's Modulus & GPa & 310 & & 240 & 200 & \\
\hline Elongation & $\%$ & 0.06 & & 0.10 & 0.17 & \\
\hline Poisson's ratio & & 0.12 & & & & \\
\hline Bending Strength (in Ar) & $\mathrm{MPa}$ & 300 & 300 & & 320 & 300 \\
\hline Interlaminar Shear Strength (in Ar) & MPa & 25 & & 15 & & \\
\hline Compressive Strength (In Plane) & $\mathrm{MPa}$ & 300 & & 340 & & 300 \\
\hline Compressive Strength (Out Plane) & $\mathrm{MPa}$ & 1400 & & 790 & & 620 \\
\hline Thermal Expansion (In Plane) & $\times 10^{-6} \mathrm{~K}^{-1}$ & 3.20 & 4.55 & & 4.66 & \\
\hline Specific heat (In Plane) & $\mathrm{J} \mathrm{g}^{-1} \mathrm{~K}^{-1}$ & 0.66 & 1.51 & & 1.54 & \\
\hline Specific heat (Out Plane) & $\mathrm{J} \mathrm{g}^{-1} \mathrm{~K}^{-1}$ & 0.65 & 1.33 & & 1.38 & \\
\hline Thermal Conductivity (In Plane) & $\mathrm{W} \mathrm{m}^{-1} \mathrm{~K}^{-1}$ & 77.7 & 36.4 & & 33.1 & \\
\hline Thermal Conductivity (Out Plane) & $\mathrm{W} \mathrm{m}^{-1} \mathrm{~K}^{-1}$ & 44.8 & 23.6 & & 22.2 & \\
\hline
\end{tabular}

Table 2. Summary of wear properties derived from this work.

\begin{tabular}{cccc}
\hline Load $(\mathrm{N})$ & $\mathrm{v}\left(\mathrm{mm} \mathrm{s}^{-1}\right)$ & Friction coefficient & Wear rate $\left(\mathrm{mm}^{3} \mathrm{MJ}^{-1}\right)$ \\
\hline 2 & 100 & $0.618(9)$ & 90 \\
5 & 100 & $0.570(5)$ & 128 \\
5 & 50 & $0.614(7)$ & 94 \\
5 & 25 & $0.610(9)$ & 139 \\
10 & 100 & $0.541(7)$ & 155 \\
\hline
\end{tabular}

\section{List of figures.}

1. Schematic of the pin on disk tribometer used in the tribological tests and a detail of the displacement of the two triboelements that is being measured by the sensor. A) shows the initial situation before the tribological test. Displacement sensor takes this 
position of the triboelements as a reference. B) Represents a situation in which wear of the disk occurs. Displacement sensor measurement corresponds to this wear. C) In this case wear of the two triboelements takes place so sensor measurement is the sum of these two contributions.

2. SEM images of a representative cross-section of the as-fabricated material in backscattered electrons contrast, in a plane containing the fibre mat stacking direction (a) and in a plane perpendicular to the pressing direction (b). Fibres in both orientations are clearly visible. Darker contrast in the core of the fibres is indicative of a $\mathrm{C}$ rich region.

3. X-Ray diffraction patterns of the as fabricated SA-Tyrannohex both in and out of the fibre plane. XRD shows that the material is highly crystalline and composed mostly of $\beta$-SiC (orange marks) with small amounts of h-graphite (green marks).Differences in the relative intensity of the peaks for both orientations are indicative of a possible crystallographic texture.

4. Friction coefficient of the SA-Tyrannohex material against a $\mathrm{Si}_{3} \mathrm{~N}_{4}$ ball versus sliding distance under three different applied loads at a sliding speed of $100 \mathrm{~mm} / \mathrm{s}$. The value of the friction coefficient decreases with the increase of the applied load.

5. Total displacement of the $\mathrm{Si}_{3} \mathrm{~N}_{4}$ ball relative to the SA-Tyrannohex disk versus sliding distance under three different applied loads at a sliding speed of $100 \mathrm{~mm} / \mathrm{s}$. The change in the distance between the two triboelements is the sum of the linear wear contributions from both elements.

6.a) Surface profile of worn surface of the SA-Tyrannohex material after the tests performed under three different normal loads at a sliding speed of $100 \mathrm{~mm} / \mathrm{s}$. Resolution in worn track depth is $1 \mathrm{~nm}$ and resolution in distance is $0.5 \mu \mathrm{m}$. The worn track depth and width increase with the increase in the applied load. b) Wear rate of the two triboelements versus normal load for the experiments carried out at a sliding speed of $100 \mathrm{~mm} / \mathrm{s}$. Wear rate shows no significant dependence with normal load. Wear rate of the $\mathrm{Si}_{3} \mathrm{~N}_{4}$ ball is an order of magnitude smaller than that of the SA-Tyrannohex material.

7. Secondary electron imaging (SEI) SEM micrographs of worn surface of the SATyrannohex material after tests carried out at a sliding speed of $100 \mathrm{~mm} / \mathrm{s}$ under normal loads of $2 \mathrm{~N}$ (a), $5 \mathrm{~N}$ (b) and 10N (c) and at sliding speeds of $50 \mathrm{~mm} / \mathrm{s}$ (d) and $25 \mathrm{~mm} / \mathrm{s}$ 
(e-f) under a normal load of 5N. Black arrows show the sliding direction. White arrows point to the boundary of the wear scar. Image (b) and (f) show a high magnification inside the wear track region presenting an area inside the scar.

8. Friction coefficient of the SA-Tyrannohex material against a $\mathrm{Si}_{3} \mathrm{~N}_{4}$ ball versus sliding distance at three different sliding speeds under an applied load of 5N. Friction coefficient slightly decreases with the highest speed.

9. Total displacement of the $\mathrm{Si}_{3} \mathrm{~N}_{4}$ ball relative to the SA-Tyrannohex disk versus sliding distance at three different sliding speeds under an applied load of $5 \mathrm{~N}$. The change in the distance between the two triboelements is the sum of the linear wear contributions from both elements.

10.a) Surface profile of worn surface of the SA-Tyrannohex after the tests performed under a normal load of $5 \mathrm{~N}$ at three different sliding speeds. Resolution in worn track depth is $1 \mathrm{~nm}$ and resolution in distance is $0.5 \mu \mathrm{m}$. Worn track depth and width are similar for the three different sliding speeds.

b) Wear rate of the two triboelements versus sliding speed for the experiments carried out under a normal load of $5 \mathrm{~N}$.Wear rate shows no dependence with sliding speed. Wear rate of the $\mathrm{Si}_{3} \mathrm{~N}_{4}$ ball is an order of magnitude smaller than that of the SA-Tyrannohex material. References

1. Evans, A.G., Ceramics and Ceramic Composites as High-Temperature StructuralMaterials - Challenges and Opportunities. Philosophical Transactions of the Royal Society a-Mathematical Physical and Engineering Sciences, 1995. 351(1697): p. 511527.

2. North, B., Substitution of Ceramics for Conventional Cutting Tools. Materials and Society, 1984. 8(2): p. 257-270.

3. Jack, K.H., Sialon Tool Materials. Metals Technology, 1982. 9(Jul): p. 297-301.

4. Spitsberg, I. and J. Steibel, Thermal and environmental barrier coatings for SiC/Sic CMCs in aircraft engine applications. International Journal of Applied Ceramic Technology, 2004. 1(4): p. 291-301.

5. Corman, G.S., et al., Rig and engine testing of melt infiltrated ceramic composites for combustor and shroud applications. Journal of Engineering for Gas Turbines and Power-Transactions of the Asme, 2002. 124(3): p. 459-464. 
6. Naslain, R., Design, preparation and properties of non-oxide CMCs for application in engines and nuclear reactors: an overview. Composites Science and Technology, 2004. 64(2): p. 155-170.

7. Krenkel, W. and F. Berndt, C/C-SiC composites for space applications and advanced friction systems. Materials Science and Engineering a-Structural Materials Properties Microstructure and Processing, 2005. 412(1-2): p. 177-181.

8. Krenkel, W., B. Heidenreich, and R. Renz, C/C-SiC composites for advanced friction systems. Advanced Engineering Materials, 2002. 4(7): p. 427-436.

9. Allor, R.L. and S. Jahanmir, Current problems and future directions for ceramic machining. American Ceramic Society Bulletin, 1996. 75(7): p. 40-43.

10. Ishikawa, T., Advances in inorganic fibres. Polymeric and Inorganic Fibres, 2005. 178: p. 109-144.

11. Ishikawa, T., Crack-resistant fibre-bonded ceramic. Advanced Engineering Materials, 1999. 1(1): p. 59-61.

12. Ishikawa, T., et al., A tough, thermally conductive silicon carbide composite with high strength up to 1600 degrees $C$ in air. Science, 1998. 282(5392): p. 1295-1297.

13. Ishikawa, T., et al., High-strength alkali-resistant sintered SiC fibre stable to 2,200 degrees C. Nature, 1998. 391(6669): p. 773-775.

14. Bunsell, A.R. and M.H. Berger, Fine diameter ceramic fibres. Journal of the European Ceramic Society, 2000. 20(13): p. 2249-2260.

15. Matsunaga, T., et al., Thermomechanical Performance of Si-Ti-C-O and Sintered SiC Fibre-Bonded Ceramics at High Temperatures. International Journal of Applied Ceramic Technology, 2011. 8(2): p. 273-281.

16. Ramirez-Rico, J., J. Martinez-Fernandez, and M. Singh, Effect of oxidation on the compressive strength of sintered SiC-fibre bonded ceramics. Materials Science and Engineering a-Structural Materials Properties Microstructure and Processing, 2012. 534: p. 394-399.

17. Fischer, T.E., M.P. Anderson, and S. Jahanmir, Influence of Fracture-Toughness on the Wear-Resistance of Yttria-Doped Zirconium-Oxide. Journal of the American Ceramic Society, 1989. 72(2): p. 252-257.

18. Fischer, T.E. and H. Tomizawa, Interaction of Tribochemistry and Microfracture in the Friction and Wear of Silicon-Nitride. Wear, 1985. 105(1): p. 29-45.

19. Khedkar, J., I. Negulescu, and E.I. Meletis, Sliding wear behavior of PTFE composites. Wear, 2002. 252(5-6): p. 361-369.

20. Biscoe, J. and B.E. Warren, An X-ray study of carbon black. Journal of Applied Physics, 1942. 13(6): p. 364-371. 
21. Munro, R.G., Material properties of a sintered alpha-SiC. Journal of Physical and Chemical Reference Data, 1997. 26(5): p. 1195-1203.

22. Bryant, P.J., P.L. Gutshall, and L.H. Taylor, A study of mechanisms of graphite friction and wear. Wear, 1964. 7(1): p. 118-126.

23. Ajayi, O.O. and K.C. Ludema, Surface Damage of Structural Ceramics - Implications for Wear Modeling. Wear, 1988. 124(2): p. 237-257.

24. Griffioen, J.A., S. Blair, and W.O. Winer, Infrared surface temperature and surface distress, D. Dowson, et al., Editors. 1986, Butterworths: London. p. 238-245.

25. Wang, H.L. and M.H. Hon, Temperature dependence of ceramics hardness. Ceramics International, 1999. 25(3): p. 267-271.

26. Esposito, L., et al., Sliding wear response of an alumina-zirconia system. Journal of the European Ceramic Society, 1998. 18(1): p. 15-22. 
FIGURE 1

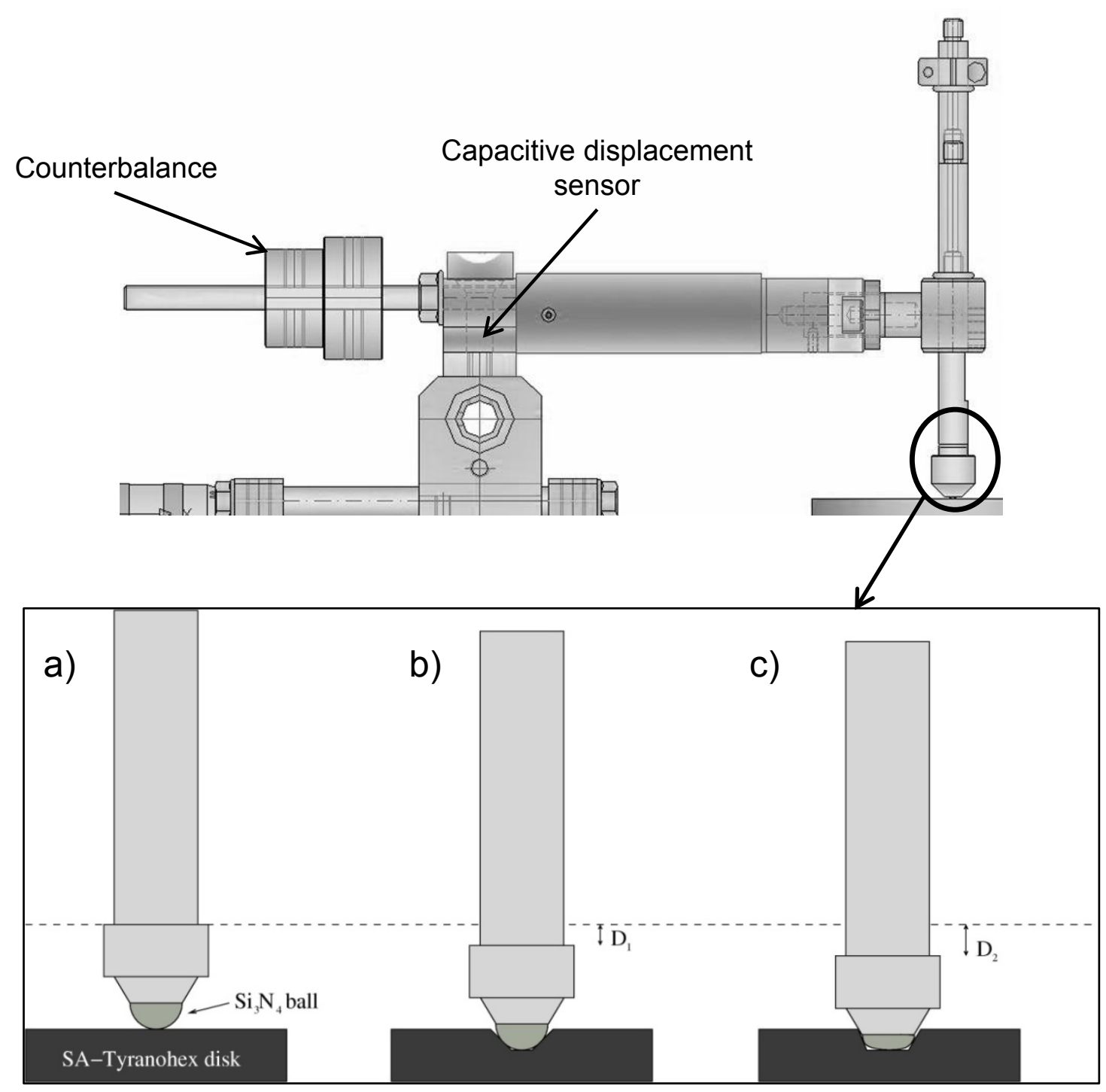




\section{FIGURE 2}

a

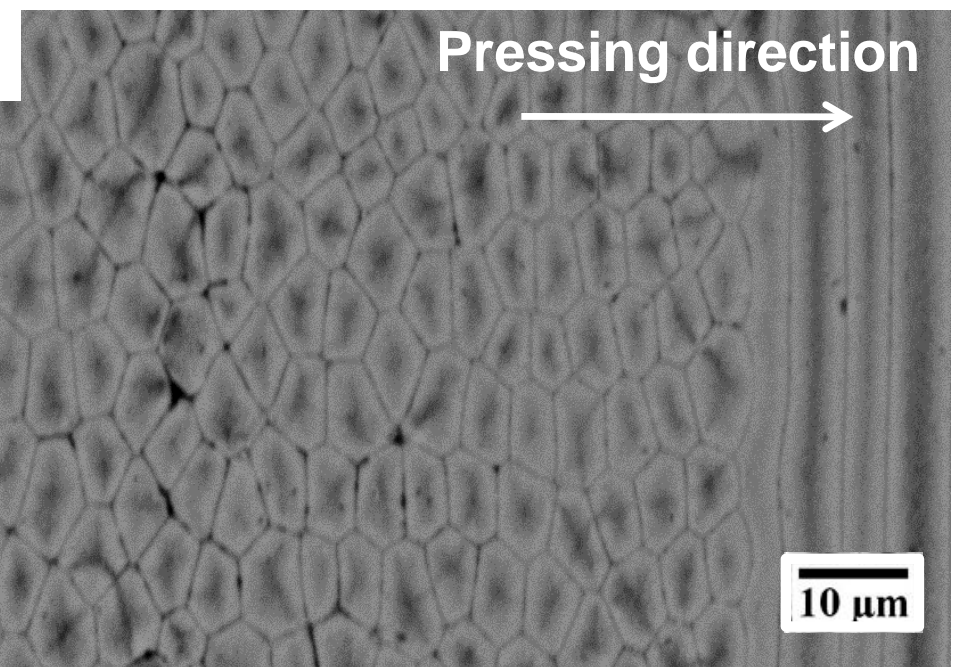

b 8 pressing direction

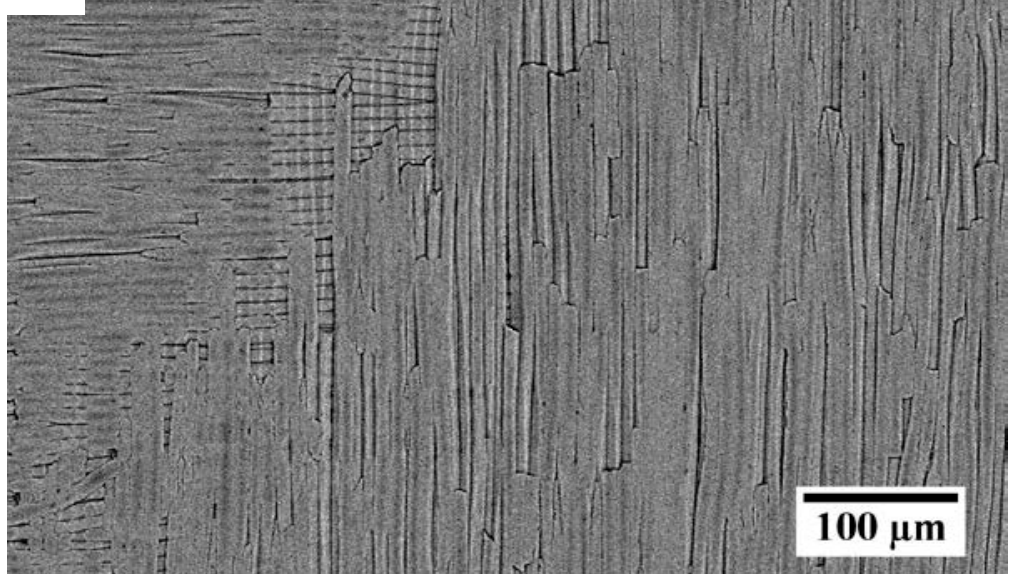


FIGURE 3

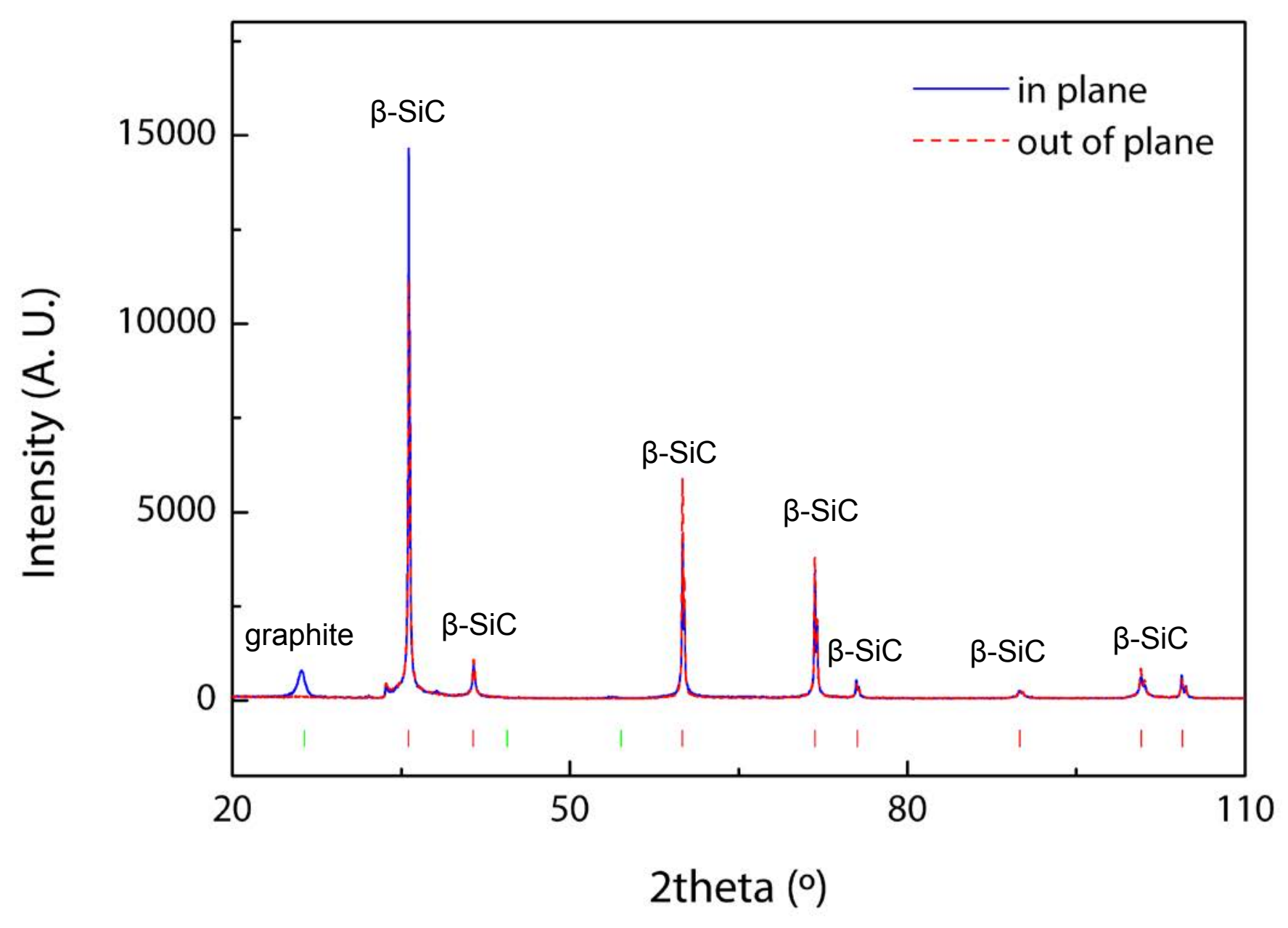




\section{FIGURE 4}

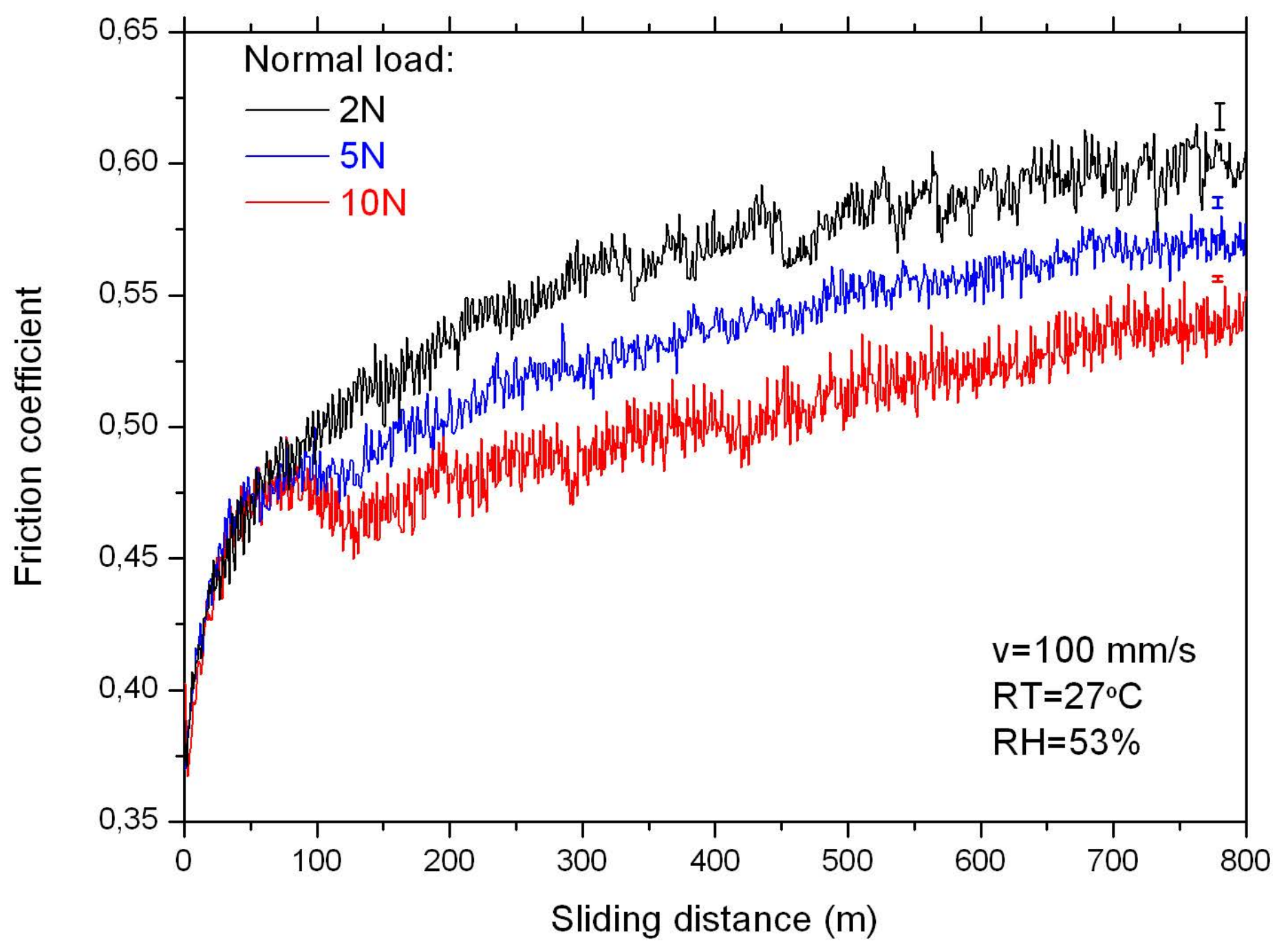




\section{FIGURE 5}

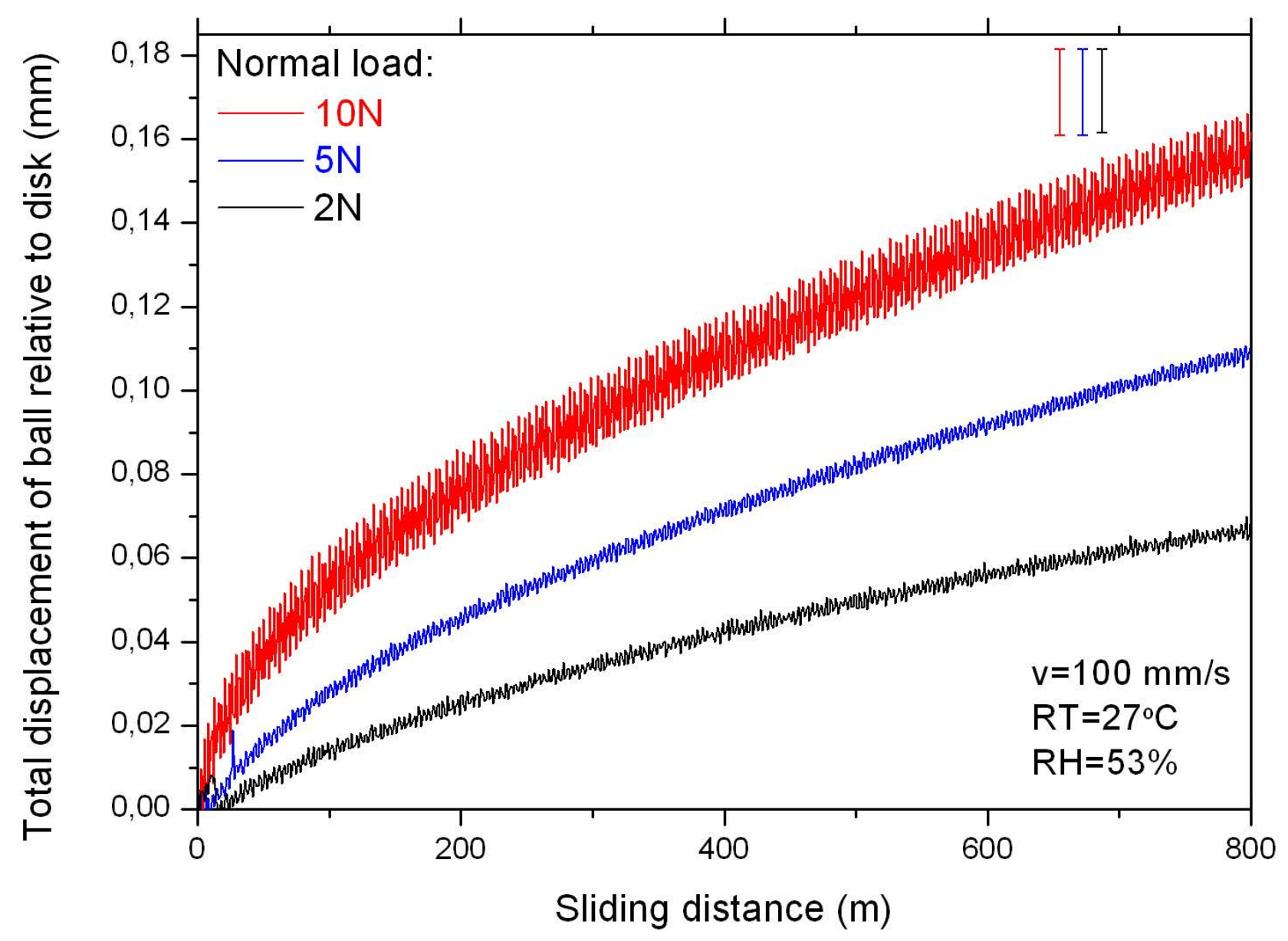




\section{FIGURE 6}

A)

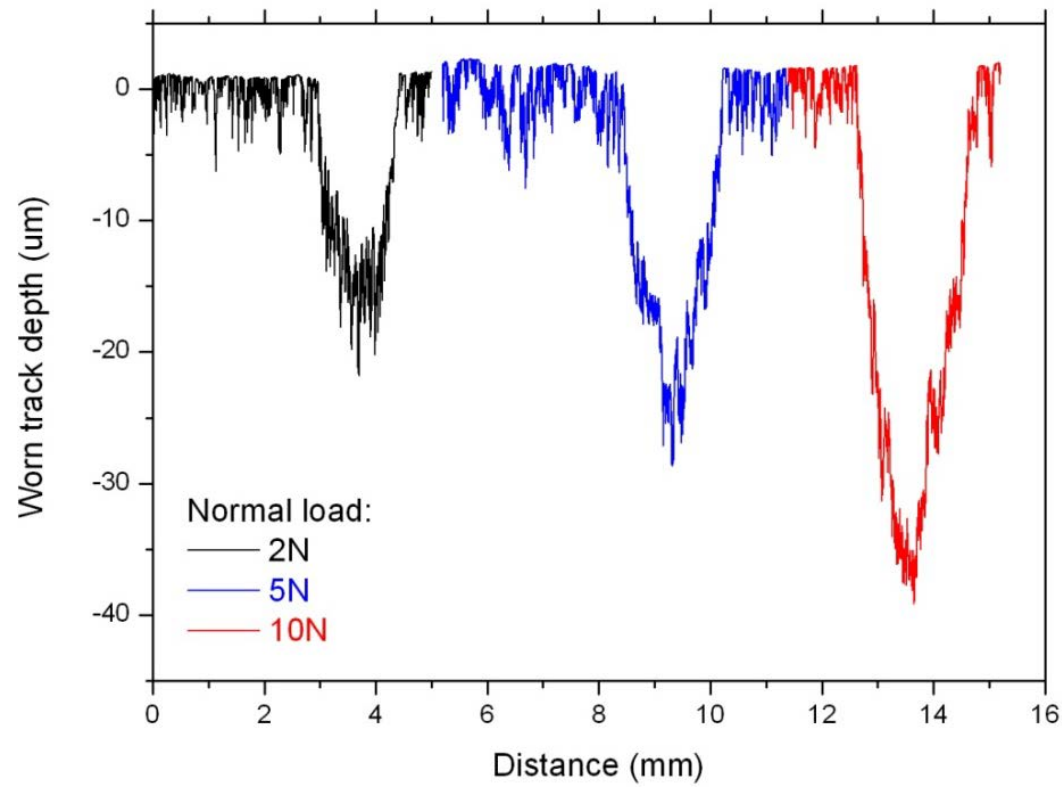

B)

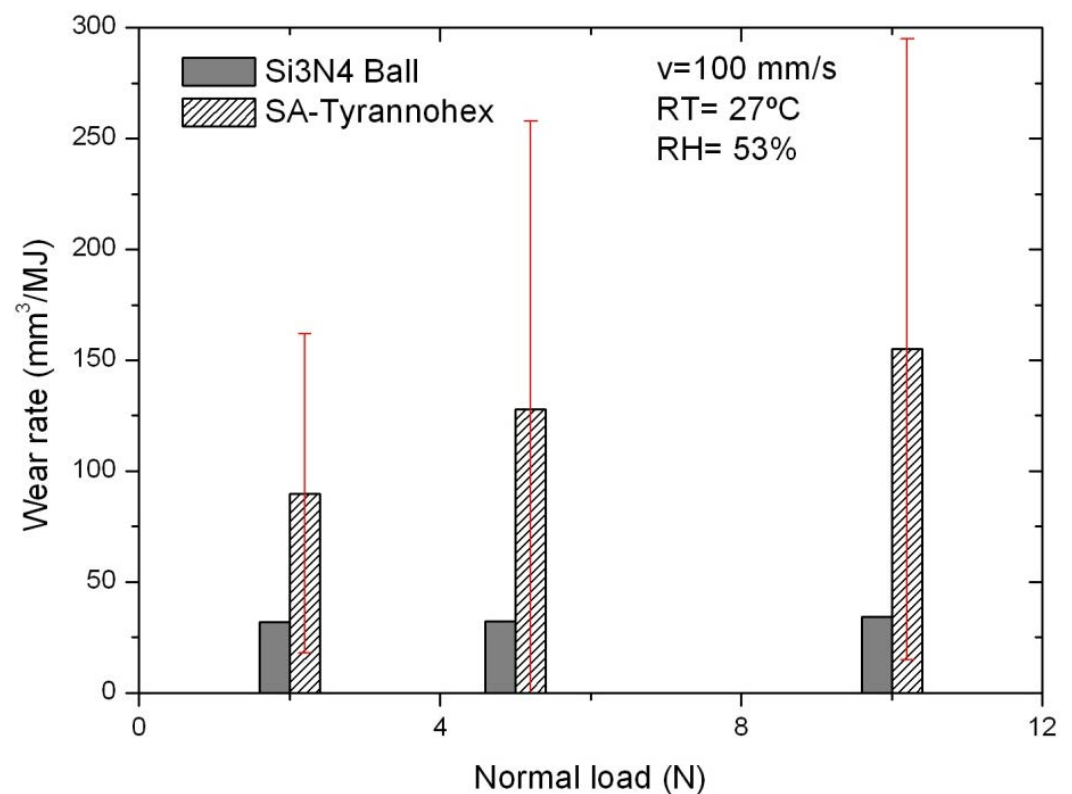




\section{FIGURE 7}
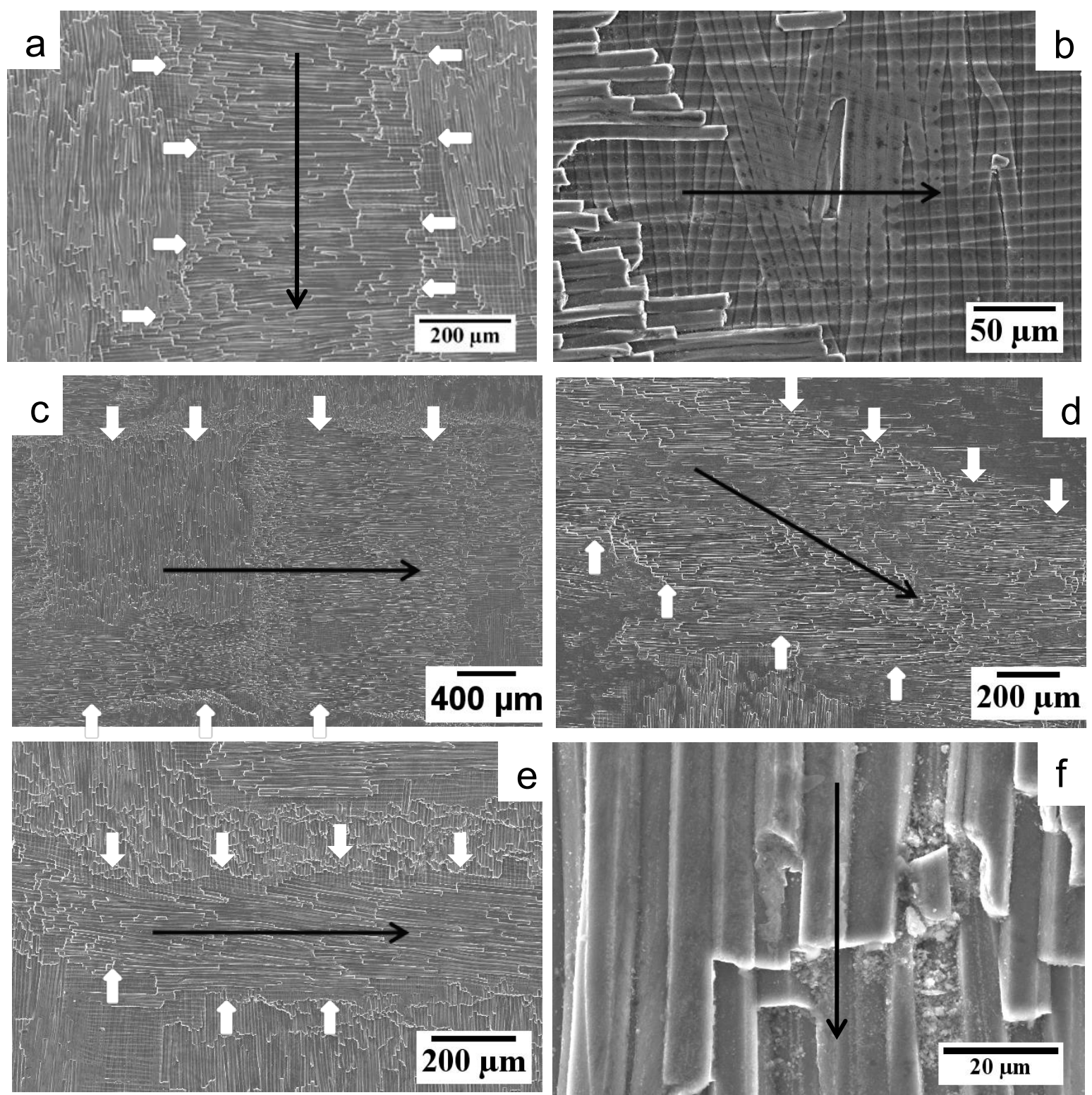


\section{FIGURE 8}

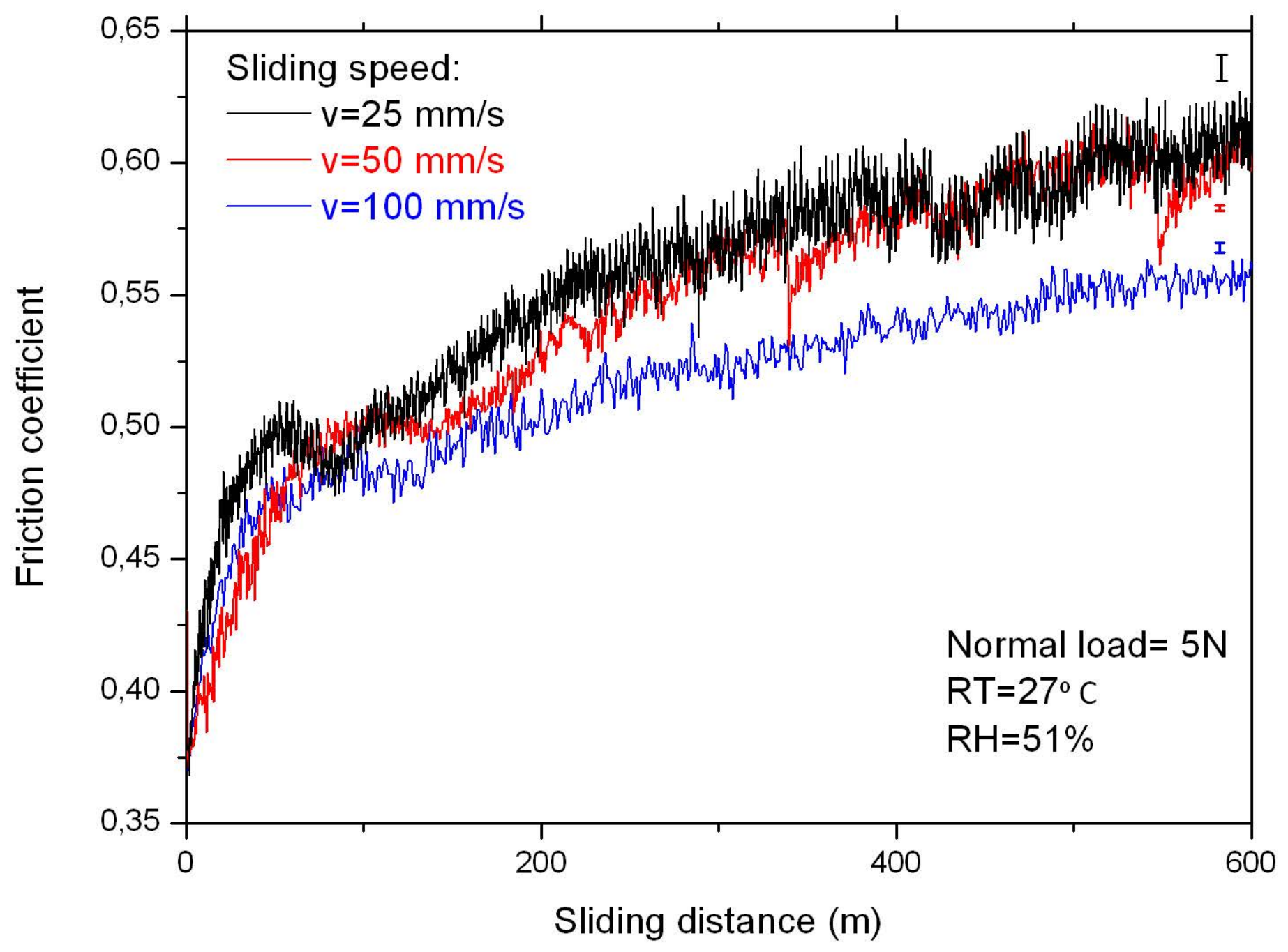




\section{FIGURE 9}

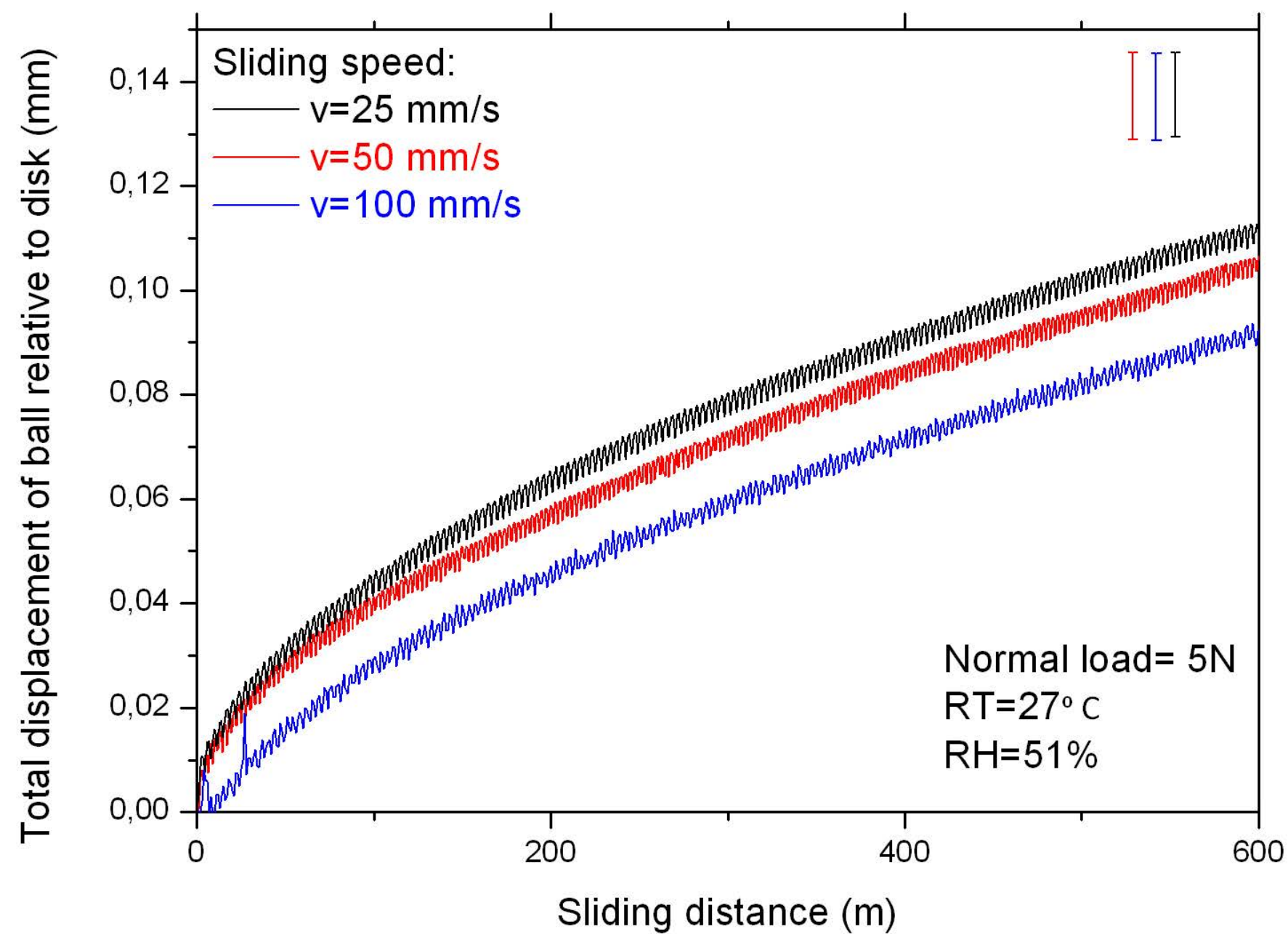




\section{FIGURE 10}

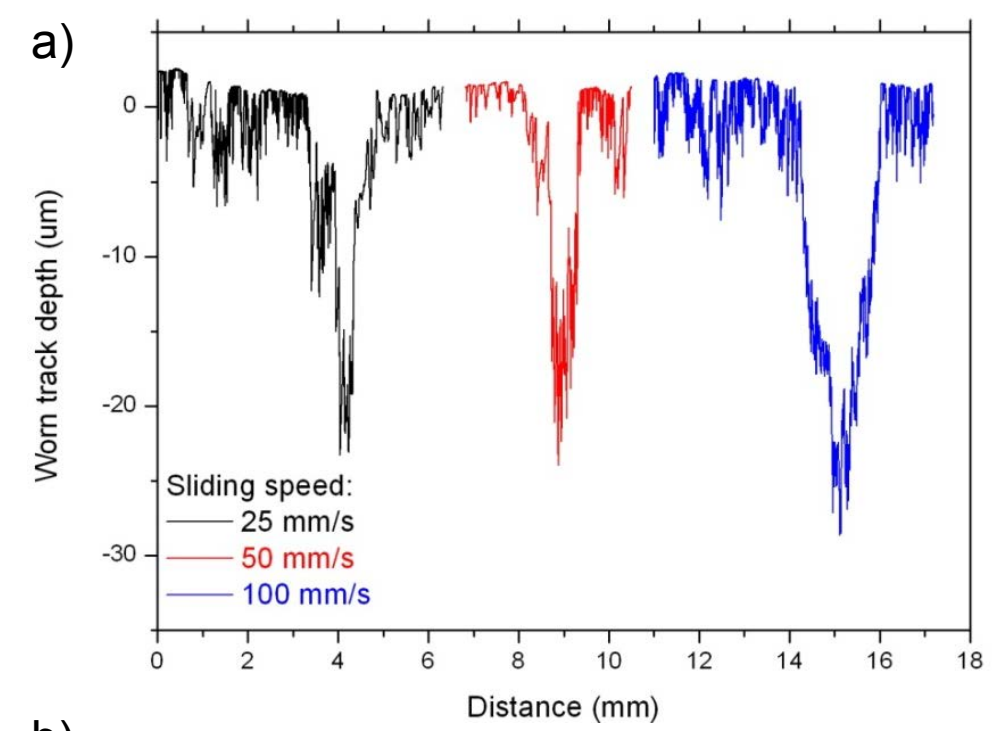

b)

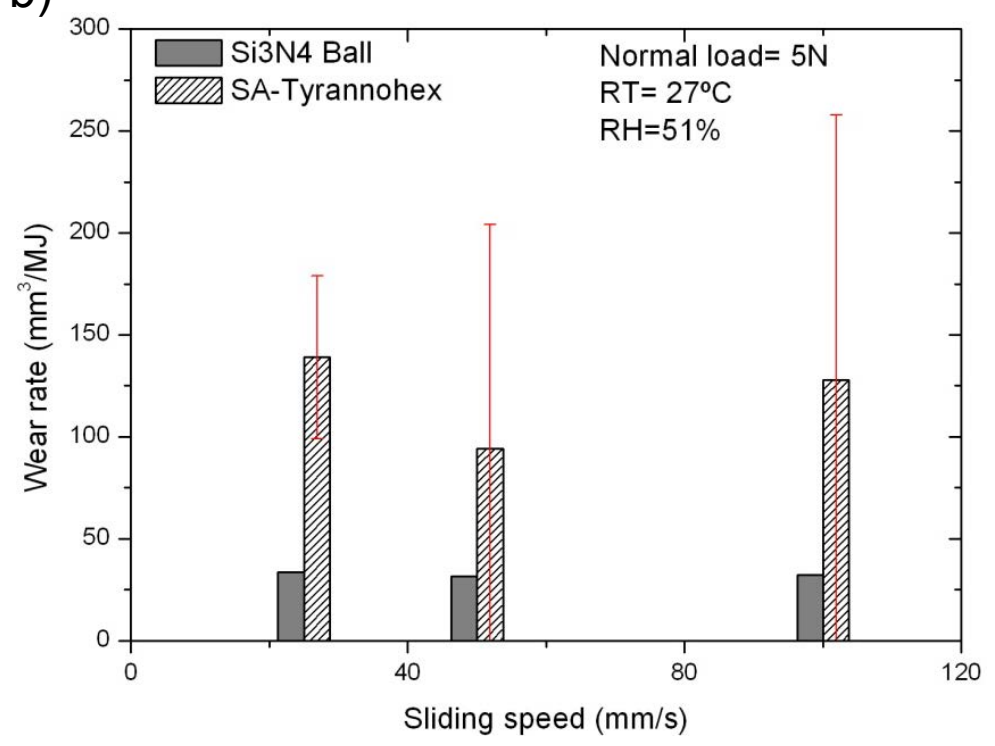

